\title{
STUDI TENTANG EFEKTIVITAS IKLAN DAN EKUITAS MEREK UNTUK MENINGKATKAN KEPUTUSAN PEMBELIAN KONSUMEN SABUN LUX DI JAWA TENGAH
}

\author{
Mudiantono \\ Departemen Manajemen \\ Fakultas Ekonomika dan Bisnis \\ Universitas Diponegoro \\ Email: mumuk_undip@yahoo.co.id \\ Astrini Setyowirasti \\ Departemen Manajemen \\ Fakultas Ekonomika dan Bisnis \\ Universitas Diponegoro \\ Email:byastrini@gmail.com
}

\begin{abstract}
Abstrak
Persaingan pasar barang konsumsi dewasa ini sangat ketat. Berbagai upaya telah dilakukan oleh perusahaan di dalam memasarkan produknya. Sabun LUX yang merupakan produk andalan bagi PT Unilever telah mengalami penurunan kinerja pemasarannya yang terlihat dari menurunnya Top Brand Index, Brand Share dan Top of Mind selama tiga tahun (2012-2014). Kalau keadaan ini terus berlangsung maka akan memperlemah posisi merek di pasar dan akan menurunkan kinerja perusahaan. Studi ini dilakukan untuk menganalisis pengaruh efektivitas iklan dan ekuitas merek (Brand Equity) terhadap keputusan pembelian dalam rangka meningkatkan kembali kinerja pemasarannya. Dengan menggunakan data dari 192 responden, delapan hipotesis diuji melalui analisis Structural Eqation Model (SEM).Hasil penelitian menunjukkan bahwa keputusan konsumen untuk membeli dipengaruhi oleh minat beli. Minat beli konsumen akan meningkat apabila iklan yang efektif dilakukan melalui peningkatan Ekuitas Merek. Iklan bisa efektif apabila mempunyai daya tarik yang tinggi. Oleh karena itu, perusahaan disarankan untuk bisa meningkatkan daya tarik iklannya sehingga iklan tersebut efektif. Dengan iklan yang efektif akan meningkatkan minat beli konsumen yang pada akhirnya akan meningkatkan keputusan pembelian.

Kata kunci:
\end{abstract}

Efektivitas Iklan, Ekuitas Merek, Keputusan Pembelian 


\begin{abstract}
The competion in consumer goods in the market is now very tight. All efforts have been done by producers to win in the market. LUX is one brand of soap produced by PT Unilever. The marketing performance of LUX has been decreased in 2012-2014. It is indicated by the decrease of Top Brand Index, Brand Share and Top of Mind during that period. If this condition is continously happened then the position of LUX will be weakened in the market. This study aimed to analyze the influence of advertising effectiveness and brand equity to purchasing decision of LUX in Central Java in order to increase the marketing performance. By using data of 192 respondents, the eight hypothesis were tested. The Structural Equation Model (SEM) was applied.This study found that the decision of consumer to buy LUX is influenced by buying intention. Buying intention will increase when the effectiveness of advertising is done. The advertising will be effective if it is interesting. So, it is suggested that the producer of LUX must make the interesting advertisement when they want to increase the purchasing decision of consumers.
\end{abstract}

Keywords:

The Advertising effectiveness, Brand Equity, Purchasing Decision. 


\section{PENDAHULUAN}

Dewasa ini industri konsumsi rumah tangga di Indonesia mengalami pertumbuhan yang begitu cepat dan cukup signifikan. Perkembangan yang pesat inilah yang akan menyebabkan munculnya persaingan antar perusahaan untuk memenuhi kebutuhan para konsumen. Perusahaan yang ingin bertahan harus memiliki keunggulan atau keunikan tersendiri yang dapat menjadikannya nilai lebih bagi perusahaan tersebut di mata perusahaan lain. Perusahaan juga harus lebih cermat dan tanggap terhadap permintaan serta kebutuhan para konsumen sehingga mereka dapat menentukan strategi dalam memenuhi permintaan serta kebutuhan para konsumen. Tahapan selanjutnya, perusahaan harus mampu mengkomunikasikan produknya kepada para calon konsumen atau target market-nya.

LUX merupakan salah satu produk sabun cair yang memberikan keyakinan pada konsumennya bahwa semua orang bisa cantik bak bintang. Karena visi dan misi LUX tersebut, produk perawatan tubuh ini memposisikan diri sebagai produk kecantikan yang di gunakan oleh kaum wanita yang mempunyai mimpi ingin tampil bak bintang ternama. Di kategori sabun mandi, ekuitas merek LUX sudah dikenal dengan baik. LUX merupakan produk sabun kecantikan dari PT Unilever Indonesia yang sudah 80 tahun eksis di pasar dan puluhan wanita cantik Indonesia pernah menjadi bintang iklannya (www.unilever.co.id). Namun popularitas, loyalitas dan ekuitas pada sabun LUX ternyata tidak menjadikannya jaminan bahwa perjalanan mereknya akan selalu baik. Berikut ini kinerja sabun LUX di Indonesia. 
Tabel 1.

Top Brand Sabun di Indonesia Tahun 2012 - 2014

\begin{tabular}{|c||c||c||c|}
\hline Brand & $\mathbf{2 0 1 2}$ & $\mathbf{2 0 1 3}$ & $\mathbf{2 0 1 4}$ \\
\hline \hline Lifebouy & 34,8 & 34,6 & 37,9 \\
\hline \hline Lux & 31,3 & 26,6 & 18,3 \\
\hline \hline Dettol & 6,1 & 9,0 & 16,3 \\
\hline \hline Biore & 9,7 & 12,7 & 10,1 \\
\hline Citra & 4,6 & 3,5 & 6,2 \\
\hline
\end{tabular}

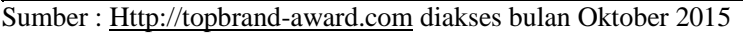

Dari Tabel 1. di atas dapat dilihat mengalami kenaikan. Angka tersebut bahwa Top Brand sabun LUX selama menunjukkan bahwa sabun Lux di mata periode 2012 - 2014 dalam posisi ke dua masyarakat menurun selama tiga tahun namun menurun dalam kurun waktu tersebut. belakangan ini.

Sementara untuk sabun merek lain

Tabel 2.

Brand Share Sabun di Indonesia Tahun 2012 - 2014 (dalam persentase)

\begin{tabular}{|c||c|c|c|}
\hline Brand & $\mathbf{2 0 1 2}$ & $\mathbf{2 0 1 3}$ & $\mathbf{2 0 1 4}$ \\
\hline \hline Lifebouy & 31,1 & 38,3 & 37,5 \\
\hline \hline Lux & 30,6 & 23,3 & 18,3 \\
\hline \hline Biore & 15,8 & 14,8 & 16,2 \\
\hline \hline Dettol & 7,4 & 5,5 & 11,6 \\
\hline \hline Citra & 5,5 & 4,2 & 3,4 \\
\hline
\end{tabular}

Sumber : Swa 20/XXVII/20 September-03 Oktober 2012, Swa 19/XXIX/20 September- dan Swa 19/XXX/11 September-24 Oktober 2014

Tabel 2. di atas terlihat bahwa Brand

Share Sabun Lux juga mengalami penurunan selama tiga tahun terakhir $(2012-2014)$. Hal ini menunjukkan bahwa kinerja penjualan dari Sabun Lux juga mengalami penurunan. Walaupun merek yang lain mengalami fluktuasi naik dan turun, namun untuk Sabun Lux yang paling konsisten penurunannya. 
Tabel 3.

Top of Mind Advertising Sabun di Indonesia Tahun 2012 - 2014

\begin{tabular}{|c||c||c|c||}
\hline Brand & $\mathbf{2 0 1 2}$ & $\mathbf{2 0 1 3}$ & $\mathbf{2 0 1 4}$ \\
\hline \hline Lifebouy & 29,3 & 34,1 & 37,8 \\
\hline \hline Lux & 46,4 & 36,2 & 33,0 \\
\hline \hline Biore & 7,6 & 9,7 & 8,9 \\
\hline \hline Dettol & 3,7 & 4,6 & 7,4 \\
\hline Nuvo & 4,3 & $*$ & 3,8 \\
\hline
\end{tabular}

Sumber: Swa 20/XXVII/20 September-03 Oktober 2012, Swa 19/XXIX/12-20September 2013 dan Swa 19/XXX 11-24 September 2014

Pada Tabel 3. juga memperlihatkan bahwa kinerja pemasaran Sabun Lux juga mengalami penurunan selama tiga tahun terakhir (2012 - 2014). Kondisi ini apabila dibiarkan maka di masa-masa mendatang akan mendatangkan masalah. Semakin lama posisi Sabun Lux akan semakin melemah. Oleh karena itu permasalahan yang muncul adalah bagaimana meningkatkan keputusan pembelian Sabun Lux melalui efektivitas iklan dan ekuitas merek dengan mengambil objek di Jawa Tengah mengingat potensi penjualan dengan indikator jumlah penduduk yang cukup besar.

\section{KERANGKA PEMIKIRAN TEORITIS DAN PERUMUSAN HIPOTESIS}

Schiffman dan Kanuk (1994) menyatakan bahwa konsumen di dalam melakukan pembelian akan berusaha mencari informasi untuk memutuskan jenis maupun merek produk yang dipilih. Sebuah iklan merupakan cara paling efektif bagi produsen untuk mengenalkan produknya kepada para konsumen. Iklan cenderung dapat menarik konsumen untuk melakukan pembelian terhadap suatu produk (Handoyo, 2004). Kemenarikan sebuah iklan merupakan salah satu faktor yang cukup kuat untuk menarik perhatian konsumen dalam jumlah yang besar. Menurut Keller (2001) dan 
Kasali (2007) dalam bukunya mengatakan bahwa ekuitas merek yang kuat akan berdampak juga pada loyalitas konsumen dan profit perusahaan. Maka dari itu untuk mampu bersaing di pasaran dan menjaga loyalitas konsumennya, produsen harus mampu meningkatkan ekuitas merek dan efektivitas iklannya agar dapat meningkatkan volume penjualan produk.

\subsection{Pengaruh Daya Tarik Iklan terhadap Efektivitas Iklan}

Sebuah iklan harus mampu memiliki daya tarik tersendiri dalam menyampaikan sebuah pesan kepada konsumen. Iklan yang menarik akan mendapat perhatian lebih dari konsumen dan membuat iklan tersebut menjadi efektif (Shimp, 2000). Penelitian yang digunakan sebagai sebagai dasar penggunaan variabel ini adalah penelitian yang dilakukan oleh Sufa dan Munas (2012) dengan studi kasus Mie Sedap. Penelitian tersebut menjelaskan bahwa daya tarik iklan berpengaruh positif terhadap efektivitas iklan. Hal ini berarti menunjukan bahwa daya tarik merupakan salah satu faktor yang dapat meningkatkan efektivitas iklan (Riyanto, 2008) . Berdasarkan uraian tersebut diatas maka diajukan hipotesis sebagai berikut:

H1 : Daya tarik iklan berpengaruh positif terhadap efektivitas iklan.

\subsection{Pengaruh Kredibilitas Celebrity Endorser terhadap Efektivitas Iklan}

Kredibilitas endorser adalah seorang figur ataupun objek yang merepresentasikan sebuah merek yang dapat dipercaya kebenarannya dalam menyampaikan pesan iklan (Hasson, 2008). Oleh karena itu, perusahaan memiliki harapan dengan menggunakan selebriti sebagai endorser yang membuat konsumen dapat lebih mudah mengenal merek tersebut sehingga meningkatkan efektivitas iklannya. 
Penelitian yang dilakukan Riyanto (2008), Legasari et al. (2013) dan Astiyanti (2015) menyatakan bahwa celebrity endorser berpengaruh positif dan signifikan terhadap efektivitas iklan. Penggunaan bintang iklan (endorser) yang memiliki kredibilitas baik di mata konsumen akan dapat mengefektifkan fungsi iklan. Dengan pemilihan endorser yang memiliki kredibilitas baik dimata konsumen maka akan lebih membuat fungsi iklan tersebut semakin efektif (Wiryawan dan Pratiwi, 2009). Berdasarkan uraian tersebut diatas maka diajukan hipotesis sebagai berikut:

$\mathrm{H} 2$ : Celebrity endorser berpengaruh positif terhadap efektivitas iklan.

\subsection{Pengaruh Kredibilitas Celebrity Endorser terhadap Brand Equity}

Untuk meningkatkan eksistensinya di dalam persaingan, perusahaan melakukan berbagai cara dimana salah satunya dengan komunikasi yang efektif. Komunikasi yang efektif adalah saat audiens atau konsumen mampu menyerap yang disampaikan perusahaan. Ini dapat diwujudkan salah satunya melalui penggunaan endorser (Eka dan Saliman, 2001; Astiyanti, 2015). Penyampaian isi pesan sebuah iklan dapat diwakilkan dengan adanya endorser (model iklan) yang terpercaya (memiliki kredibilitas). Wiryawan dan Pratiwi (2009) mengatakan bahwa kredibiltas celebrity endorser secara positif terbukti mempengaruhi ekuitas merek (brand equity) berarti dimana pemasar hendaknya mampu melakukan analisis yang tepat sebelum memilih seorang endorser. Pemilihan endorser yang tepat dapat meningkatkan kredibilitas merek juga ekuitas merek dari perusahaan tersebut (Erdogan et al. 2001). Berdasarkan uraian tersebut di atas maka diajukan hipotesis sebagai berikut:

\section{H3 : Kredibilitas Celebrity Endorser berpengaruh positif terhadap Brand Equity}




\subsection{Pengaruh Efektivitas Iklan terhadap Brand Equity}

Periklanan bagi konsumen merupakan sumber utama informasi tentang merek beserta atribut produk lainnya. Maka konsumen akan menilai sebuah merek melalui informasi - informasi yang didapatkan dari iklan. Ekuitas sebuah merek merupakan suatu aset perusahaan yang terbentuk dari berbagai aspek (Mehta, 1994; Eka dan Saliman, 2001). Penelitian yang dilakukan Steenkamp et al. (2005) yang didukung oleh Soebijanto dan Kunto (2013) menghasilkan bahwa efektivitas iklan berpengaruh secara positif terhadap ekuitas merek. Berdasarkan uraian tersebut di atas maka diajukan hipotesis sebagai berikut :

H4 : Efektivitas iklan berpengaruh positif terhadap brand equity.

\subsection{Pengaruh Efektivitas Iklan terhadap Minat Beli}

Iklan dikatakan efektif apabila iklan tersebut berhasil menarik perhatian audiens terhadap merek sehingga memunculkan keinginan atau minat untuk membeli produk dari merek yang diiklankan. Shimp (2000) dalam bukunya yang didukung oleh Yuliastono dan Suryandari (2013) menjelaskan bahwa tujuan sebuah iklan dibuat salah satunya agar dapat mempengaruhi niatan konsumen untuk membeli. Jika sebuah iklan dapat semakin banyak menarik konsumen maka dapat dikatakan semakin efektif iklan itu, karena dapat meningkatkan minat beli dari konsumen. Penelitian yang dilakukan oleh Suherman (2011) menghasilkan adanya pengaruh positif dari variabel efektivitas iklan dan signifikan terhadap minat beli. Apabila efektivitas iklan semakin tinggi maka minat beli konsumen juga semakin tinggi (Pranata dan Arum, 2013). 
Berdasarkan uraian tersebut di atas maka diajukan hipotesis sebagai berikut :

H5 : Efektivitas iklan berpengaruh positif terhadap minat beli

\subsection{Pengaruh Brand Equity terhadap Minat beli}

Kotler dan Armstrong (2004) dan Ferdinand (2002) menyatakan bahwa ekuitas merek merupakan efek positif diferensiasi yang dapat diketahui melalui respon konsumen terhadap suatu produk barang atau jasa. Sehingga bisa dikatakan brand equity adalah kekuatan yang dimiliki oleh suatu merek yang dapat menambah atau mengurangi nilai dari merek itu sendiri. Hal ini dapat dinilai melalui respon konsumen terhadap barang atau jasa yang dijual. Penelitian yang dilakukan oleh Agusli dan Kunto (2003), Jalilvand dan Samiei (2011), Tharmi dan Senthilnathan menghasilkan bahwa variabel ekuitas merek yang terdiri dari brand awareness, brand association, perceived quality, dan brand loyalty, berpengaruh signifikan terhadap minat beli. Sehingga kekuatan dari brand equity dapat mempengaruhi minat beli konsumen terhadap suatu produk barang atau jasa. Berdasarkan uraian tersebut diatas maka diajukan hipotesis sebagai berikut:

H6 : Brand Equity berpengaruh positif terhadap Minat Beli.

\subsection{Pengaruh Brand Equity terhadap Keputusan Pembelian}

Aaker (1996) menyatakan bahwa suatu merek yang kuat dapat membantu perusahaan untuk mempertahankan identitas dari perusahaan tersebut. Ekuitas merek merupakan aset utama bagi suatu perusahaan, sehingga perusahaan harus memperjuangkan dan memperhatikan aspek ekuitas mereknya. Keputusan pembelian yang dilakukan konsumen berlangsung melewati beberapa faktor antara lain pertimbangan penilaian merek di mata 
konsumen (Iriani, 2011). Menurut hasil penelitian dari Nigam dan Khausik (2011), Doorstar et al. (2012), Irwanti (2013), Kurniawan (2012) dan Lukman (2014) bahwa variabel brand equity berpengaruh positif dan kuat terhadap keputusan pembelian produk oleh konsumen. Sehingga konsumen juga akan mempertimbangkan ekuitas merek sebuah produk sebelum menentukan keputusan pembeliannya. Berdasarkan uraian tersebut diatas maka diajukan hipotesis sebagai berikut:

H7 : Variabel Brand Equity berpengaruh positif terhadap Keputusan Pembelian.

\subsection{Pengaruh Minat Beli terhadap Keputusan Pembelian}

Minat membeli konsumen belum diikuti suatu tindakan untuk membeli, namun hanyalah muncul hasrat atau keinginan untuk membeli. Apabila konsumen mempunyai minat untuk membeli suatu barang, maka konsumen tersebut akan menunjukkan sikap positif dan perasaan senang terhadap barang tersebut, sehingga konsumen akan memanifestasikan minat tersebut dengan tindakan membeli. Penelitian yang dilakukan oleh Yoestini dan Eva (2007) dan Mahendrayasa et al (2014) menunjukkan bahwa minat beli berpengaruh signifikan terhadap keputusan pembelian. Minat beli konsumen yang tinggi akan mendorong konsumen untuk membeli suatu produk. Berdasarkan uraian tersebut diatas maka diajukan hipotesis sebagai berikut.

H8 : Minat beli berpengaruh positif terhadap keputusan pembelian.

Berikut Gambar 1. menunjukkan kerangka pemikiran teoritis penelitian. 


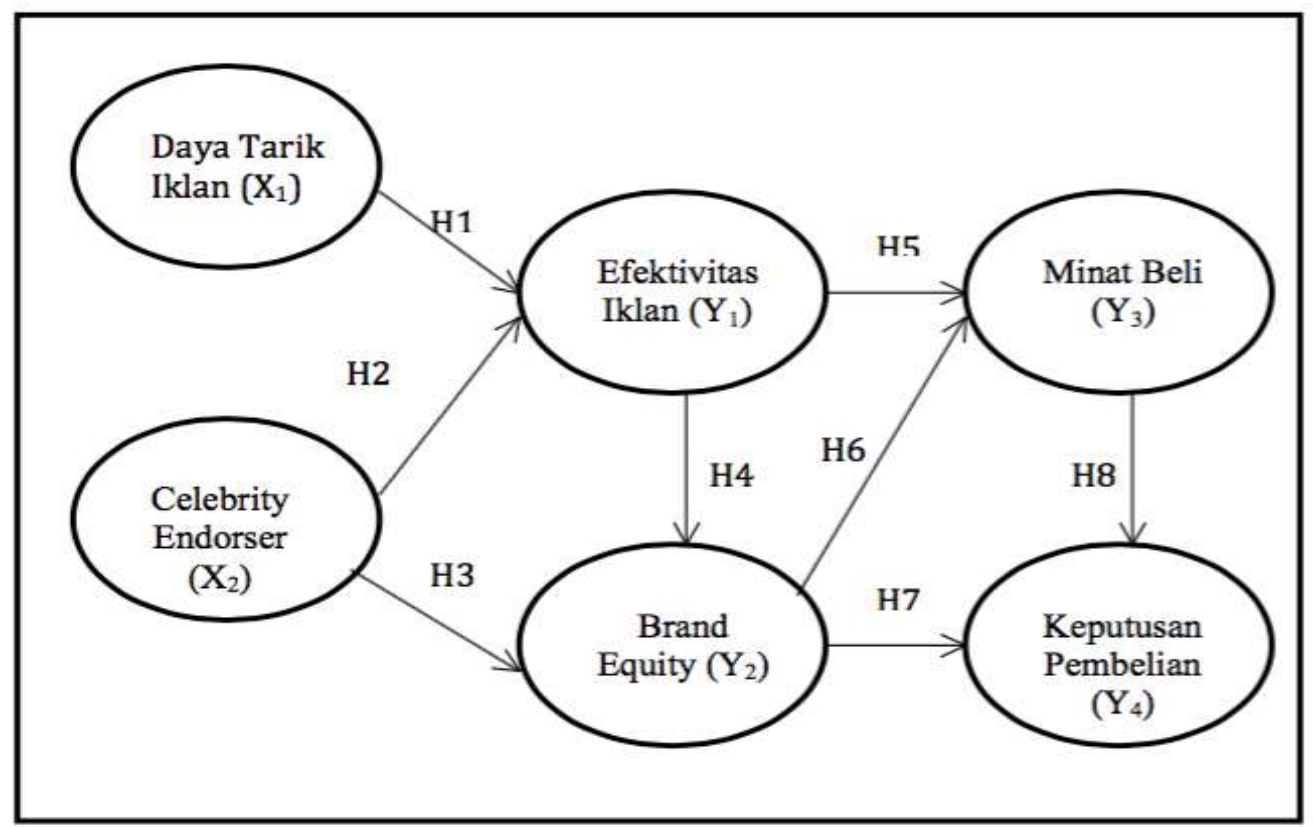

Sumber : Agusli dan Kunto (2003), Yoestini dan Eva (2007), Wiryawan dan Pratiwi (2009), Sufa dan Munas (2012) Irwanti (2013), Soebijanto dan Kunto (2013) dan Astiyanti(2015)

\section{Gambar 1.}

Kerangka Pemikiran Teoritis

\section{METODE PENELITIAN}

\subsection{Variabel Penelitian}

Berikut ini Tabel 4. menunjukkan

variabel dan indikator yang dipakai dalam

penelitian ini. 
Tabel 4.

Variabel Penelitian dan Indikator

\begin{tabular}{|c|c|}
\hline Variabel Penelitian & Indikator \\
\hline Daya Tarik Iklan & $\begin{aligned} & \text { 1. } \text { Meaningful (memiliki makna) } \\
& \text { 2. } \text { Distinctive (berbeda dari pesaing) } \\
& \text { 3. } \text { Believable (dapat dipercaya) } \\
& \text { (Riyanto ,2008; Sufa dan Munas, 2012) }\end{aligned}$ \\
\hline Celebrity Endorser & $\begin{array}{l}\text { 1. Daya tarik celebrity endorser } \\
\text { 2. Keahlian celebrity endorser } \\
\text { 3. Celebrity endorser yang terpercaya } \\
\text { (Eka dan Saliman, 2001; Wiryawan dan Pratiwi, } \\
\text { 2009; Astiyanti, 2015) }\end{array}$ \\
\hline E Efektivitas Iklan & $\begin{array}{c}\text { 1. Iklan mudah diingat } \\
\text { 2. Pesan mudah dipahami } \\
\text { 3. Iklan menarik perhatian } \\
\text { (Yulistiano dan Suryandari, 2003; Hasson, 2008; } \\
\text { Wiryawan dan Pratiwi, 2009; Astiyanti, 2015) }\end{array}$ \\
\hline Brand Equity & $\begin{aligned} & \text { 1. } \text { Sadar merek } \\
& \text { 2. } \text { Sadar kualitas } \\
& \text { 3. } \text { Loyal merek } \\
& \text { 4. } \text { Pilihan utama } \\
& \text { (Wiryawan dan Pratiwi, 2009; Sufa dan Munas, } \\
& \text { 2012; Soebijanto dan Kunto, 2013) }\end{aligned}$ \\
\hline Minat Beli & $\begin{aligned} & \text { 1. } \text { Minat Transaksional (minat untuk } \\
& \text { bertransaksi). } \\
& \text { 2. } \\
& \text { Minat Eksploratif (Minat untuk mencari } \\
& \text { informasi mengenai merek tersebut). } \\
& \text { 3. Minat Referensial (Minat mereferensikan } \\
& \text { produk kepada orang lain). } \\
& \text { (Mehta, 1994; Yoestini dan Eva, 2007) } \\
&\end{aligned}$ \\
\hline Keputusan Pembelian & $\begin{aligned} & \text { 1. } \text { Kemantapan pada sebuah produk } \\
& \text { 2. Memberikan rekomendasi kepada orang lain } \\
& \text { 3. Memprioritaskan pembelian produk } \\
& \text { (Yoestini dan Eva, 2007; Mahendrayasa, 2014) }\end{aligned}$ \\
\hline
\end{tabular}

\subsection{Populasi dan Sampel}

Menurut Ferdinand (2006), populasi merupakan gabungan dari berbagai elemen yang berbentuk peristiwa, hal, atau orang yang memiliki karakteritik serupa dan menjadi pusat perhatian seorang peneliti, karena itu dinilai sebagai sebuah penelitian. Sampel adalah subset dari populasi, terdiri dari beberapa anggota populasi (Ferdinand, 2006). Metode pengambilan sampel yang 
digunakan dalam penelitian ini adalah metode accidental sampling. Penggunaan metode Accidental sampling ini karena dianggap mudah, dapat cepat digunakan, dan sangat ideal karena dengan populasi yang terlalu besar akan mustahil untuk menyertakan setiap individu. Sampel dalam penelitian ini sebanyak 192 responden yaitu konsumen yang melakukan pembelian sabun LUX di Jawa Tengah. Hal ini sesuai dengan tujuan penelitiaan yang ingin meneliti tentang keputusan pembelian sabun merek LUX oleh konsumen di Jawa Tengah.

\subsection{Metode Analisis Data}

Alat analisis data yang digunakan yaitu Structural Equation Modeling atau SEM, yang dioperasikan melalui program AMOS. Adapun peniliti memilih menggunakan SEM dalam model dan pengujian hipotesis karena SEM merupakan sekumpulan teknik-teknik statistikal yang memungkinkan pengujian sebuah rangkaian hubungan simultan rumit. Melalui program AMOS Ghozali (2011) mengajukan tahapan pemodelan dan analisis persamaan struktural menjadi 7 (tujuh) langkah, yaitu :

- Pengembangan model secara teoritis

- Menyusun diagram jalur (path diagram)

- Mengubah diagram jalur menjadi persamaan struktural

- Memilih matriks input untuk analisis data

- Menilai identifikasi model struktural

- Menilai Kriteria Goodness-of-Fit

- Menginterpretasikan terhadap model

\section{HASIL PENELITIAN DAN} PEMBAHASAN

Hasil pengolahan data akan digambarkan melalui Tabel 5. dan Tabel 6. serta Gambar 2. berikut : 
Tabel 5.

Hasil Pengujian Kelayakan Model Structural Equation Model (SEM)

\begin{tabular}{|l||c||l|l||}
\hline \multicolumn{1}{|c|}{ Goodness of fit indeks } & Cut of Value & Output & Evaluasi Model \\
\hline Chi square & Kecil & 169,448 & Baik \\
\hline Probability & $>0,05$ & 0,065 & Baik \\
\hline \hline GFI & $>0,90$ & 0,881 & Marginal \\
\hline AGFI & $>0,90$ & 0,910 & Baik \\
\hline \hline TLI & $>0,90$ & 0,983 & Baik \\
\hline \hline CFI & $>0,90$ & 0,986 & Baik \\
\hline \hline NFI & $>0,90$ & 0,919 & Baik \\
\hline \hline RMSEA & $<0,08$ & 0,031 & Baik \\
\hline
\end{tabular}

Sumber : Data primer yang diolah, 2016

Nilai chi square merupakan nilai yang paling penting untuk menandakan bahwa model yang digunakan dapat diterima dengan baik dan kriteria indeks pengukuran yang lain akan menjadi penunjangnya. Dari Tabel 5. didapatkan nilai chi square sebesar 112,788. Selain itu nilai GFI, AGFI, TLI, CFI, NFI, dan RMSEA telah sesuai dengan yang digunakan dapat diterima dengan baik.

Model penelitian ini dapat diterima dengan baik juga telah didukung dengan kriteria indeks pengukuran yang berada pada rentang nilai yang diharapkan. Dengan demikian dapat disimpulkan bahwa uji kelayakan model SEM sudah memenuhi syarat penerimaan.

kriteria yang menunjukkan bahwa model

Tabel 6.

Regression Weight Structural Equational

\begin{tabular}{|c|c|c|c|c|c|c|c|}
\hline & & & Estimate & S.E. & C.R. & $\mathrm{P}$ & Label \\
\hline Efektivitas Iklan & $<--$ & Daya Tarik Iklan & ,662 & ,093 & 7,085 & $* * *$ & par_14 \\
\hline Efektivitas Iklan & <--- & Celebrity endorser & 289 & 082 & 3,540 & $* * *$ & par_15 \\
\hline Brand equity & <--- & Celebrity endorser & ,004 & ,171 & ,026 & \begin{tabular}{|l||}
, 979 \\
\end{tabular} & par_16 \\
\hline Brand equity & <--- & Efektivitas Iklan & ,965 & ,191 & 5,057 & $* * *$ & par_17 \\
\hline Minat Beli & $<---$ & Efektivitas Iklan & ,280 & ,101 & 2,770 &, 006 & par_18 \\
\hline Minat Beli & <--- & Brand equity & ,493 & ,082 & 5,974 & $* * *$ & par_19 \\
\hline Keputusan Pembelian & $<--$ & Brand equity & ,403 &, 175 & 2,305 & \begin{tabular}{|l|}
021 \\
\end{tabular} & par_20 \\
\hline Keputusan Pembelian & <--- & Minat Beli & ,498 & ,239 & 2,082 & $\mid 037$ & par_21 \\
\hline
\end{tabular}




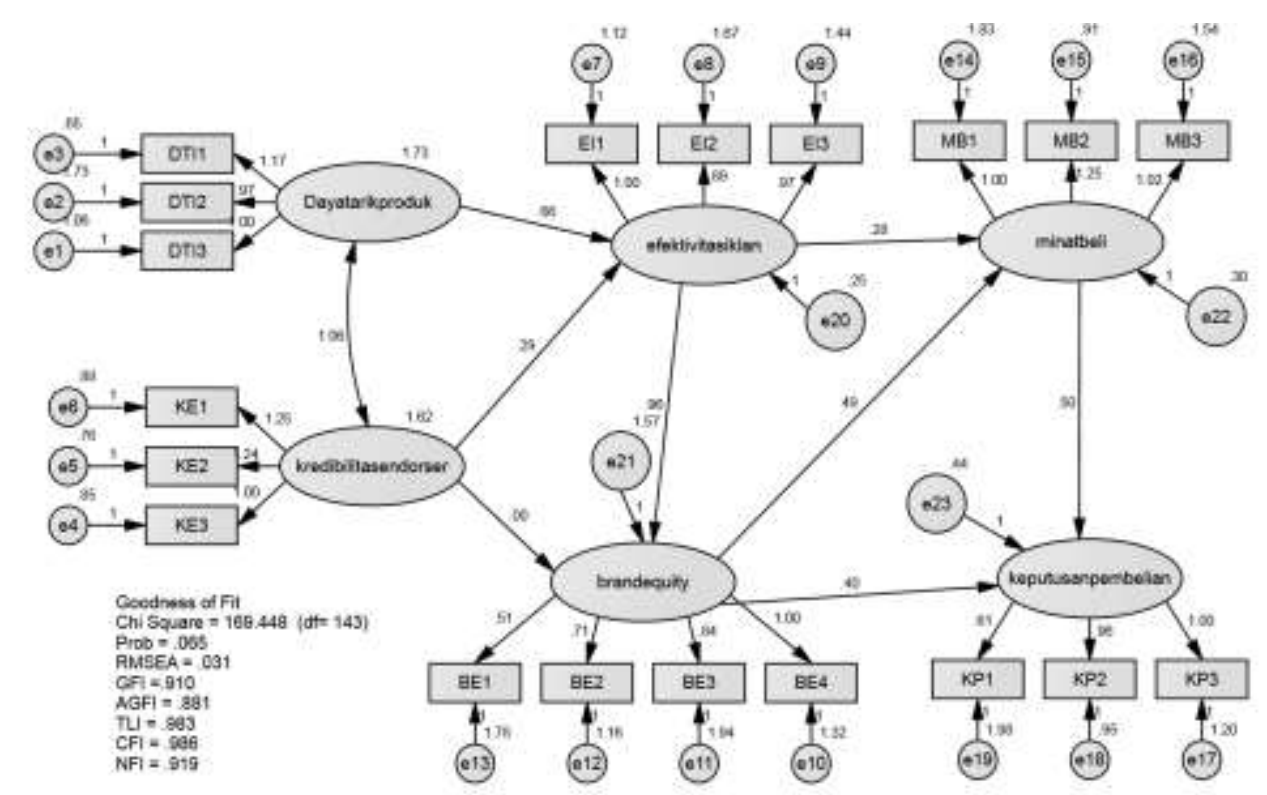

Sumber : Data primer yang diolah, 2016

Gambar 2.

Full Model SEM

Hipotesis yang telah diformulasikan

telah diuji berdasarkan pada kriteria bahwa

Critical Ratio (CR) dan nilai Probability (P).

Secara statistik, untuk bisa menerima hipotesis apabila nilai CR di atas 1,96 dan P di bawah 0,05. Dari hasil analisis diketahui bahwa delapan hipotesis yang telah dibuat dapat diterima semuanya.

Hipotesis 1 yang menunjukkan bahwa daya tarik iklan berpengaruh positip terhadap efektivitas iklan. Penelitian ini telah mendukung pendapat Shimp (2000), Riyanto (2008) serta Sufa dan Munas (2012) yang mengatakan bahwa agar supaya iklan menjadi efektif, maka iklan harus mempunyai daya tarik.

Hipotesis 2 membuktikan bahwa pemakaian celebrity endorser yang kredibel akan meningkatkan efektivitas iklan. Ini mendukung pendapat dari Hasson (2008), Riyanto (2008), Wiryawan dan Pratiwi (2009), Legasari et al. (2013) dan Astiyanti 
(2015) yang menyatakan bahwa pengunaan bintang iklan yang memiliki kredibilitas yang baik di mata konsumen akan mengefektifkan fungsi iklan.

Hipotesis 3 memberi konfirmasi bahwa kredibilitas celebrity endorser meningkatkan brand equity secara tidak signifikan. Temuan ini tentunya berbeda dengan penelitian yang dilakukan oleh Eka dan Saliman (2001), Erdogan et al. (2001), Wiryawan dan Pratiwi (2009) dan Astiyanti (2015) bahwa kredibilitas celebrity endorser berpengaruh positif secara signikan.

Hipotesis 4 menyatakan bahwa efektivitas iklan berpengaruh positif terhadap brand equity adalah terbukti. Hasil temuan ini telah mendukung pendapat Mehta (1994), Eka dan Saliman (2001) serta Subijanto dan Kunto (2013) yang mengatakan bahwa iklan yang efektif itu akan meningkatkan ekuitas merek.

Hipotesis 5 menjelaskan kejadian bahwa iklan yang efektif itu benar secara signifikan berpengaruh secara positif terhadap minat beli konsumen. Pendapat dari Shimp (2000), Yuliastono dan Suryandari (2013) dan Suherman (2011) yang mengatakan bahwa iklan yang efektif akan membuat konsumen mempunyai niat untuk membeli produk telah didukung oleh penelitian ini.

Hipotesis 6 menjustifikasi bahwa brand equity berpengaruh positif terhadap minat beli. Temuan ini sesuai dengan pendapat Kotler dan Amstrong (2004), Ferdinand (2002), Agusli dan Kunto (2003), Jalilvand dan Samiei (2011) serta Tharmi dan Senthilnathan (2012) yang menyatakan bahwa brand equity itu merupakan kekuatan yang dimiliki oleh suatu merek yang bisa menambah nilai merek sehingga menambah respon positif niat konsumen untuk memilih merek.

Hipotesis 7 mengkonfirmasi bahwa brand equity mempunyai pengaruh positif terhadap keputusan pembelian. Hal ini 
mendukung pendapat yang dikemukakan oleh Aaker (1996), Iriani (2011), Nigam dan Khausik (2011), Doorstar et al. (2012), Kurniawan (2012), Irwanti (2013) dan Lukman (2014) yang menyatakan bahwa brand equity merupakan aset utama perusahaan sehingga konsumen yang ingin memilih produk tentunya akan mempertimbangkan kekuatan aset tersebut.

$$
\text { Hipotesis } 8 \text { menyatakan semakin }
$$
tinggi minat beli maka keputusan untuk membeli juga semakin tinggi. Pendapat demikian sejalan dengan pendapat Schiffman dan Kanuk (2008) dan Mahendrayasa et al. (2014) yang mengatakan bahwa apabila konsumen mempunyai minat untuk membeli suatu merek maka konsumen tersebut akan menunjukkan sikap positif yang pada akhirnya akan memilih merek itu.

\section{KESIMPULAN DAN IMPLIKASI MANAJERIAL}

\subsection{Kesimpulan}

Hasil penelitian menunjukkan bahwa semua hipotesis dapat diterima walaupun ada satu hipotesis yang berpengaruh secara lemah yaitu hipotesis yang menyatakan bahwa Celebrity Endorser berpengaruh positif terhadap Brand Equity. Hasil penelitian memberi kesimpulan bahwa keputusan pembelian itu dipengaruhi oleh Minat Beli dengan nilai koefisien regresi sebesar $(0,498)$ yang lebih besar dari koefisien regresi brand equity $(0,409)$. Selanjutnya minat beli dipengaruhi oleh brand equity $(0,493)$ yang lebih besar dari efektivitas iklan (0,280). Sementara besarnya Brand Equity dipengaruhi oleh Efektivitas Iklannya (0,965). Iklan akan menjadi efektif apabila mempunyai Daya Tarik yang tinggi dengan koefisien regresi sebesar 0,662 . 


\subsection{Implikasi Manajerial}

Dari temuan penelitian seperti tampak pada kesimpulan di atas, maka implikasi manajerialnya bisa disusun. Perusahaan produsen LUX disarankan untuk malakukan langkah-langkah sebagai berikut :

Langkah 1 : meningkatkan daya tarik iklan. Variabel daya tarik iklan ini dibentuk oleh tiga indikator yang masing-masing meaningful, distinctive dan believable. Oleh karena itu, produk LUX sebaiknya menggunakan kalimat yang persuasif dan efektif kemudian memiliki konsep iklan yang berbeda dari pesaing serta menyampaikan informasi yang dapat dipercaya oleh konsumen.

Langkah 2 : membuat iklan menjadi efektif. Efektivitas iklan mempunyai indikator iklan mudah diingat, pesan mudah dipahami dan iklan menarik perhatian. Sabun merek LUX sebaiknya memberi perhatian kepada pesan yang disampaikan. Oleh karena itu, untuk bisa menarik masyarakat untuk mau memperhatikan perlu dicari pesan yang mudah dipahami serta menarik perhatian. Pemilihan celebrity endorser yang tepat bisa dipertimbangkan untuk dipakai mengingat masyarakat Indonesia yang masih menyukai bentuk informasi secara visual.

Langkah 3 : meningkatkan brand equity. Variabel brand equity dibentuk oleh indikator-indikator sadar merek, sadar kualitas, loyal merek dan menjadi pilihan utama. Sabun merek LUX seharusnya tetap bisa menjaga kualitas dan menjaga loyalitas merek sehingga akan selalu menjadi pilhan utama.

Langkah 4 : menjaga minat beli konsumen tetap tinggi. Variabel ini dibentuk oleh tiga indikator yaitu minat bertransaksi, minat exploratif dan minat referensial. Langkah yang bisa diambil adalah dengan cara penyuguhan iklan dengan cara unik dengan konsep unik dengan bintang iklan yang sesuai sehingga bisa menarik konsumen 
Studi Tentang Efektivitas ... (Mudiantono dan Astrini Setyowirasti)

untuk membeli, meskipun pengaruh variabel

celebrity endorser berpengaruh lemah

terhadap brand equity. 


\section{DAFTAR PUSTAKA}

Aaker, David A. 1996. Manajemen Ekuitas Merek, Jakarta: Spektrum Mitra.

Agusli, Devonalita dan Yohanes Sondang Kunto. 2013. “Analisa Pengaruh Dimensi Ekuitas Merek Terhadap Minat Beli Konsumen Midtown Hotel Surabaya," Jurnal Manajemen Pemasaran Petra Vol. 1 (2).

Astiyanti, Gita Aprilia. 2015. "Pengaruh Daya Tarik Iklan, Kreativitas Iklan dan Kredibilitas Endorser Terhadap Efektivitas Iklan dan Minat Beli pada Minuman Serbuk Buah Merek Nutrisari (Studi pada Masyarakat di Kota Malang”. Jurnal Bisnis dan Manajemen, Universitas Brawijaya Malang.

Doorstar, Mohammad, Maryam Kazemi Imam Abadi dan Reza Kazemi Imam Abadi. 2011. "Impact of Brand Equity on Purchase Decision of Final Cosumer Focusing on Products with Low Mental Conflict". Journal of Basic and Applied Scientific Research Vol. 2 No. 10.

Eka, Rita dan A.R. Suliman. 2001. "Periklanan yang Efektif”, Jurnal Ekonomi Perusahaan, Juli.

Erdogan, B.Z., M.J. Baker dan S. Taggs. 2001. "Selecting Celebrity Endorser : The Practitioner's Perspectives". Journal of Advertising Researches. 41(3): 39-48.

Ferdinand, Augusty Tae. 2002. Pengembangan Minat Beli Merek Ekstensi. Semarang: Badan Penerbit Universitas Diponegoro.

Ferdinand, Augusty Tae. 2006. Metodologi Penelitian Manajemen. Edisi 2. Semarang : Badan Penerbit Universitas Diponegoro .

Ghozali, Imam. 2011. Aplikasi Analisis Multivariate Dengan Program IBM SPSS 19 (edisi kelima.) Semarang: Universitas Diponegoro.

Handoyo, Sapto. 2004. "Pengaruh Kreativitas Iklan Terhadap Loyalitas Konsumen", Telaah Bisnis, Vol 5 (2), UPN Veteran Yogyakarta.

Hasson, Bruno. 2008. Fashion Branding, Gramedia Pustaka Utama, Jakarta.

Http://topbrand-award.com diakses pada Oktober 2015.

Iriani, Ika Ida. 2011. "Pengaruh Dimensi Brand Equity (Ekuitas Merek) Terhadap Keputusan Pembelian pada Kartu Telepon Seluler Telkomsel di Kota Malang”, Jurnal Aplikasi Manajemen, Vol. 9.

Irwanti, Ika. 2013. "Analisis Pengaruh Brand Equity Terhadap Proses Keputusan Pembelian Pada Konsumen Pond's Di Kota Surabaya", Jurnal Ekonomi dan Bisnis Universitas Katholik Widya Mandala Surabaya, Volume 2 (4).

Jalilvand, Mohammad Reza dan Neda Samiei. 2011. "The Effect of Electronic Word of Mouth on Brand Image and Purchase Intention : An Emperical Study in the Aautomobile Industry in Iran". Marketing Intelligent and Planning Vol. 30.

Legasari, Vioneta Eka, Sri Indarti dan Sri Restuti. 2013. "Pengaruh Daya tarik Iklan, Kreativitas Iklan dan Kredibilitas Endorser terhadap Efektivitas Iklan dan Sikap Konsumen pada Sabun Pemutih Wajah Merek Oil of Oley di Kota Pekanbaru”. Jurnal Ekonomi Vol.21 No.3 : 1-15.

Kasali, Renald .2007. Membidik Pasar Indonesia Segmentasi Targeting Positioning, Gramedia Pustaka Utama, Jakarta.

Kotler, Philip dan Gary Amstrong. 2004. Prinsip-prinsip Marketing. Penerbit Salemba Empat, Jakarta.

Kurniawan, Saverius Dwi. 2012. "Analisis Pengaruh Brand Loyalty, Brand Image, Iklan dan Perceived Quality terhadap Minat Beli Konsumen XL Prabayar di Kota Surabaya”. Jurnal Universitas Katolik Widya mandala Surabaya, Vo. 1, No. 1.

Lukman, Marco Dirgadi. 2014. "Analisis Pengaruh Ekuitas Merek Terhadap Keputusan Pembelian Konsumen Teh Botol Sosro Kemasan Kotak". Jurnal Administrasi Bisnis Vo. 14.

Mahendrayasa, Kumadji dan Abdillah. 2014. "Pengaruh Word of Mouth terhadap Minat Beli serta Dampaknya pada Keputusan Pembelian", Jurnal Marketing 1(5) 46-54 .

Mehta, Abhilasha. 1994. "How Advertising Response Modelling (ARM) can Increase Ads Effectiveness", Journal of Marketing Research, May/June, pp. 62-74. 
Nigam, Ashutosh dan Rajiv Khausik. 2011. "Impact of Brand Equity on Consumer Purchase Decision: An Empirical Investigation with Special Reference to Hatchback Car Owner in Central Haryana". IJCEM International Journal of Computational Engineering and Management Vol. 12.

Pranata, Ardhan dan Arum Darmawati. 2013. "Pengaruh Kreativitas Iklan Terhadap Minat Beli yang Dimediasi Efektivitas Iklan (Studi pada Minuman Isotonic Merek Mizone di Kota Yogyakarta". Jurnal Manajemen Bisnis Indonesia, Vol. 2, Edisi V.

Riyanto, Makmun 2008. "Studi Mengenai Efektivitas Iklan". Jurnal Sain Pemasaran Indonesia, Vol. VII, No. 2, 125-150.

Schiffman, Leon and Leslie L. Kanuk. 2008. Perilaku Konsumen, Jakarta ; P.T. Indeks.

Shimp, A Terence. 2000. Promosi dan Periklanan. Aspek Tambahan Komunikasi Pemasaran Terpadu. Jakarta : Erlangga.

Soebijanto, Fendy dan Kunto, S.Y. 2013. "Analisa Efektifitas Program Promosi Top Gondola Kopi Kapal Api Ditinjau dari Peningkatan Ekuitas Merek dan Minat Beli (Studi Kasus Di PT Fastrata Buana Surabaya)". Jurnal Manajemen Pemasaran Petra. 2013.

Steenkamp, Jan-Benedict E.M., Vincent R. Nijs, Dominique M. Hanssens, Marnik G. Dekimpe 2005. "Competitive Reactions to Advertising and Promotion Attacks". Marketing Science, Vol. 24 No. 1 pp. 35-54.

Sufa, Faela \& Bambang Munas, 2012. "Analisis Pengaruh Daya Tarik Iklan, kualitas Pesan Iklan, Frekuensi Penayangan Iklan Terhadap Efektivitas Iklan Televisi Mie Sedap", Journal of Management". Vol 1 (1) : 226-233. Universitas Diponegoro.

Suherman, Pratama. 2011. Analisis Pengaruh Efektifitas Iklan Internet dan Kelompok Referensi terhadap Persepsi Kualitas dan Dampaknya terhadap Niat Beli Produk Blackberry. Jakarta: Universitas Islam Negeri Syarif Hidayatullah.

Swa 20/XXVII/September - Oktober 2012.

Swa 19/XXIX/20 September - Oktober 2013.

Swa 19/XXX/11-24 September 2014.

Tharmi, Uthayakumar dan Samithamby Senthilnathan 2012. "The Relationship of Brand Equity to Purchase Intention”. IUP Journal Marketing Management.

Wiryawan, Driya dan Anisa Pratiwi 2009. "Analisis Pengaruh Celebrity Endorser Terhadap Brand Image pada Iklan Produk Kartu Prabayar XL Bebas di Lampung”, Jurnal Bisnis dan Manajemen, 5 (4-32).

www.merdeka.com diakses pada bulan Oktober 2015.

www.unilever.co.id diakses pada bulan Oktober 2015.

Yoestini dan Eva S. 2007. "Analisis Pengaruh Kualitas Layanan dan Citra Merek terhadap Minat Beli dan Dampaknya pada Keputusan Pembelian”. Jurnal Sains Pemasaran Indonesia. Vol. VI (3) : 261-276.

Yulistiano, Muhammad dan Retno Tanding Suryandari. 2003, "Pengukuran Advertising Response Modelling (ARM) Iklan Televisi dengan Endorser Selebritis", Emperika, Vol.16 (2). Desember 2003, UNS Surakarta. 